\title{
O design de Luís Jardim: pesquisa, catalogação e difusão da memória gráfica pernambucana
}

\author{
The design of Luís Jardim: research, cataloging and \\ dissemination of Pernambuco's graphic memory
}

Bruno Pereira Verissimo, Sílvio Romero Botelho Barreto Campello

Luís Jardim, Memória Gráfica de Pernambuco, Metodologia, História do Design

Este artigo relata o processo metodológico da pesquisa nos acervos que resultou no site "O Design de Luís Jardim". Para isso adaptou-se o método "Conjunto Metodológico para Pesquisa em História do Design a partir de Materiais Impressos" (2016) com o objetivo de catalogar e criar um banco de dados online com as obras que o artista gráfico Luís Jardim produziu para a imprensa pernambucana das décadas de 1920 e 1930. Portanto, o objetivo deste artigo é apresentar todo o processo da pesquisa, bem como as adaptações ao método, algumas experiências da catalogação e a contribuição do design da informação nestes tipos de estudo.

Luís Jardim, Pernambuco Graphic Memory, Methodology, History of Design

This paper reports the methodological process of research in the collections that resulted in the website "O Design de Luís Jardim". For this, the method "Methodological Procedures for Design History Research from the analysis of printed materials" (2016) was adapted in order to catalog and create an online database with the works that the graphic artist Luís Jardim produced for the Pernambuco press of the 1920s and 1930s. The objective of this paper is to present the entire research process, as well as adaptations to the method, some cataloging experiences and the contribution of information design in these types of study.

\section{Introdução}

Se as pessoas não tiverem vínculos profundos com sua memória ancestral, com as referências que dão sustentação a uma identidade, vão ficar loucas neste mundo maluco que compartilhamos (KRENAK, 2019).

Apesar das duas décadas de pesquisa sobre o campo da Memória Gráfica no Brasil, o muito que foi feito durante este período é somente o começo promissor, como bem pontuado pelo historiador Rafael Cardoso (2018). Os arquivos se tornaram o ambiente fundamental desses pesquisadores, as metodologias se apresentam como ferramentas cada vez mais sólidas na condução de tais pesquisas e o campo vem se expandindo e se ramificando nas mais diversas experiências regionais do país. Está mais que claro que, em termos culturais, somos diversos brasis dentro de um mesmo território e investigar nossa cultura material a partir

Anais do $10^{\circ} \mathrm{CIDI}$ e $10^{\circ} \mathrm{CONGIC}$

Kelli C.A.S. Smythe, Rafael de Castro Andrade (orgs.)

Sociedade Brasileira de Design da Informação - SBDI

Curitiba | Brasil | 2021
Proceedings of the $10^{\text {th }} \mathrm{CIDI}$ and $10^{\text {th }}$ CONGIC

Kelli C.A.S. Smythe, Rafael de Castro Andrade (orgs.)

Sociedade Brasileira de Design da Informação - SBDI Curitiba | Brazil | 2021 
dessa diversidade é a principal forma de construirmos uma História do Design essencialmente brasileira.

Priscila Farias e Marcos da Costa Braga (2018), descrevem que a principal e ampla meta final dos estudos de Memória Gráfica é a de inserir os artefatos gráficos na cultura, na memória e na identidade local de um povo, através de resgate e constituição de acervos de fontes primárias de material gráfico para futuras consultas.

A pesquisa de mestrado "O Design de Luís Jardim: Ilustrações e Artes Gráficas para a Imprensa Periódica Pernambucana do começo do Século XX" (2020) teve como um dos objetivos o resgate de uma parte da produção gráfica de Luís Jardim, resultando em um banco de dados das obras que o artista produziu em Pernambuco nas décadas de 1920 e 1930. Para isso foi realizada visita a acervos e coleta do material, seguindo o método "Conjunto Metodológico para Pesquisa em História do Design a partir de Materiais Impressos" (2016) proposto por Letícia Pedruzzi Fonseca, Daniel Dutra Gomes e Adriana Pereira Campos.

Ao final do processo da pesquisa de mestrado foi criado um website em formato de galeria de imagens, com parte da obra de Luís Jardim coletada durante os estudos, com o intuito de difundir o material e inseri-lo na memória das pessoas, expandindo e celebrando os estudos dos impressos efêmeros e os pioneiros do Design Gráfico.

Este artigo tem como objetivo relatar o processo metodológico da pesquisa nos acervos, que resultou no site "O Design de Luís Jardim", descrevendo as adaptações ocorridas e o uso do Design da Informação no processo. Contribuindo com as pesquisas conduzidas seguindo parâmetros semelhantes a essa e revelando a atuação e obra gráfica do artista Luís Jardim.

\section{Luís Jardim, artista gráfico}

Luís Inácio de Miranda Jardim nasceu em Garanhuns, interior de Pernambuco, em 1901. Aos 17 anos se mudou para o Recife onde teve suas primeiras digressões nas artes e na imprensa, mesmo autodidata, tendo nunca frequentado escola de arte ou pintura, se mostrou um cultor do bico de pena, possuindo uma técnica e experiência incríveis nas artes gráficas, as quais the renderam diversos trabalhos e parcerias na capital pernambucana.

No final da década de 1920 atuou intimamente nas oficinas de produção das principais publicações pernambucanas da época como a Revista do Norte; na segunda fase do jornal A Província; auxiliou no projeto gráfico da Revista de Garanhuns e colaborou em diversas capas e ilustrações para o Diário de Pernambuco e o Jornal do Commercio (Nascimento, 1966, 1967, 1994).

Também no Recife realizou parcerias com figuras influentes da época como Gilberto Freyre, o qual se tornou seu amigo pessoal, convidando-o em 1934 para ilustrar o Guia Prático, Histórico e Sentimental da Cidade do Recife, sendo esse um dos seus trabalhos de maior projeção no período, Ihe proporcionando convites para colaborar em outros guias Brasil afora (Verissimo \& Campello, 2019). 
Em 1936 a convite de Rodrigo de Melo Franco e da Sociedade Felipe de Oliveira, Jardim montou uma exposição de telas no Rio de Janeiro, na Galeria Leandro Martins, com cerca de 40 aquarelas, todas evocando aspectos do Recife e Bahia. O sucesso dessa exposição foi um dos impulsos que fez o artista se mudar para o Rio de Janeiro.

Na capital fluminense auxiliou Mário de Andrade, junto de outros intelectuais da época, na elaboração do anteprojeto de lei que deu origem ao Serviço de Patrimônio Histórico e Artístico Nacional (SPHAN), em janeiro de 1937 (IPHAN, 2007). E mais tarde, em 1955, ingressou no Instituto do Açúcar e do Álcool, no setor de Serviço de Documentação da Divisão Administrativa, onde exerceu a função de chefe da Seção de Documentação (Hélio \& Bruscky, 1998). Lá também colaborou como artista gráfico para a revista Brasil Açucareiro, publicação quinzenal distribuída em todo o Brasil.

A sua atuação como escritor de diversas obras o tornaram popular também na literatura, principalmente infantil, vencendo em duas categorias diferentes o "Concurso de Literatura Infantil do Ministério da Educação e Cultura" em 1937 pelos livros Boi Aruá e O Tatu e o Macaco, escritos e ilustrados por Jardim.

Contudo, seu trabalho de maior interesse no Rio de Janeiro foi na Editora José Olympio (JO), tendo ocupado cargo de importância nos bastidores das publicações da casa (Verissimo, 2020). O artista, assim como Santa Rosa e Cícero Dias, ilustrou e fez a capa de diversas obras publicadas pela JO, Mário Hélio e Paulo Bruscky (1998, p. 28) comentam que "só para os romances de José Lins do Rego chegou a fazer cerca de 200 desenhos".

A atuação de Luís Jardim como ilustrador e artista gráfico na capital pernambucana se apresentava, até então, desconhecida dos estudos de Memória Gráfica, ainda que seja um dos mais significativos de sua obra, tendo em vista o caráter experimental de seus primeiros trabalhos, a versatilidade com que trabalhava dentro da indústria gráfica, além de fazer parte do grupo de outros artistas e ilustradores do período.

Mesmo não deixando filhos ou herdeiros de sua arte, após seu falecimento aos 87 anos no Rio de Janeiro, Luís Jardim deixou um legado nas artes, na literatura e também no design gráfico, o qual deve ser preservado e resgatado para futuras gerações de estudantes e artistas.

\section{Processo metodológico}

Como mencionado anteriormente, utilizamos das orientações metodológicas propostas por Letícia Pedruzzi Fonseca, Daniel Dutra Gomes e Adriana Pereira Campos (2016) em "Conjunto Metodológico para Pesquisa em História do Design a partir de Materiais Impressos" fazendo algumas adaptações e mudanças. $\mathrm{O}$ modelo propõe as seguintes etapas:

\section{- Aproximação do pesquisador com o contexto} sócio-histórico do impresso

- Revisão Bibliográfica

- Entrevistas 


\section{- Análise gráfica do impresso}

- Identificação e mapeamento de acervos

- Registro fotográfico do acervo

- Organização do acervo digital

- Elaboração da ficha de análise do impresso

- Coleta de dados do impresso

- Análise estatística

- Discussão dos resultados

A partir deste modelo, o processo metodológico seguiu etapas semelhantes, contudo tendo em vista a criação do site, tencionando esse como um dos objetivos deste artigo e incorporando ao método de Fonseca et al (2016) particularidades da pesquisa a respeito de um artista gráfico, bem como os comentários de Farias e Braga (2018) sobre a inserção na sociedade dos artefatos estudados, por meio de constituição de acervos para futuras consultas, como supracitado.

Sendo assim, algumas adaptações e mudanças foram sugeridas ao método e foram seguidas durante a pesquisa, como vistas no Gráfico 1 e esmiuçadas em seguida:

Gráfico 1: Método adaptado de Fonseca et al (2016), seguido durante a pesquisa.

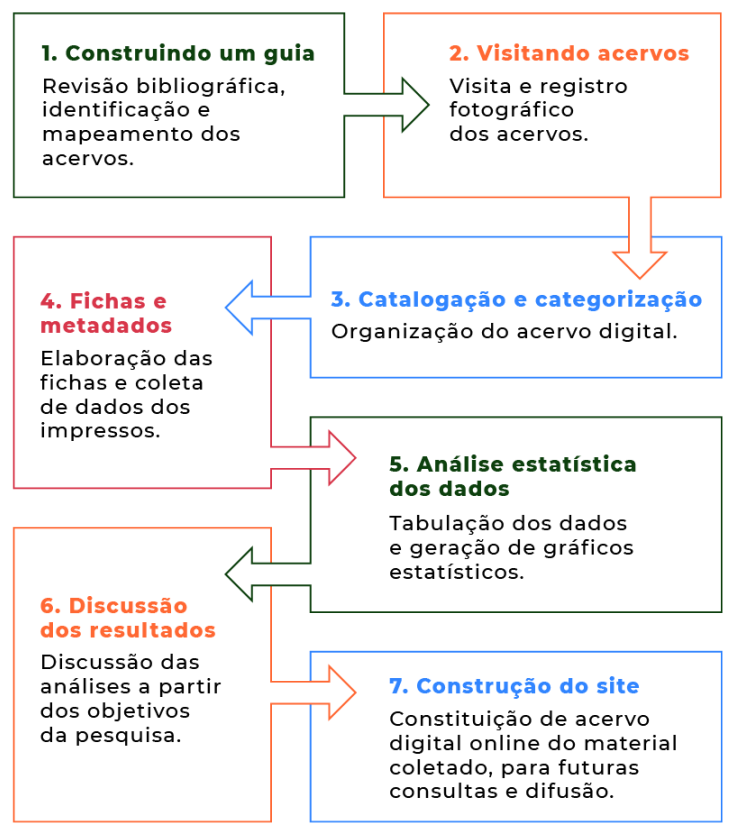

\section{Construindo um guia}

Esta pesquisa teve como fio condutor a trajetória do artista Luís Jardim, compreendendo que a melhor forma de encontrar pistas sobre sua produção gráfica seria, a princípio, investigando sua biografia. Logo, um apanhado de informações foram coletadas através da bibliografia 
escrita sobre o artista, bem como sites, publicações, entrevistas concedidas pelo mesmo ainda em vida e outras referências encontradas.

Estas informações, contidas em ambas as obras, geraram a criação de dois documentos, os quais representaram ferramentas significativas para o início e o desenrolar da pesquisa. Foram elas a criação de uma linha do tempo com fatos cronológicos sobre a vida de Luís Jardim (Gráfico 2) e uma lista de suas peças gráficas. Através desses dois arquivos de dados, pôde-se visualizar um panorama da pesquisa e a partir disso fazer recortes, estabelecer lacunas e guiar as visitas posteriores aos acervos.

Gráfico 2: Linha do tempo biográfica de Luís Jardim

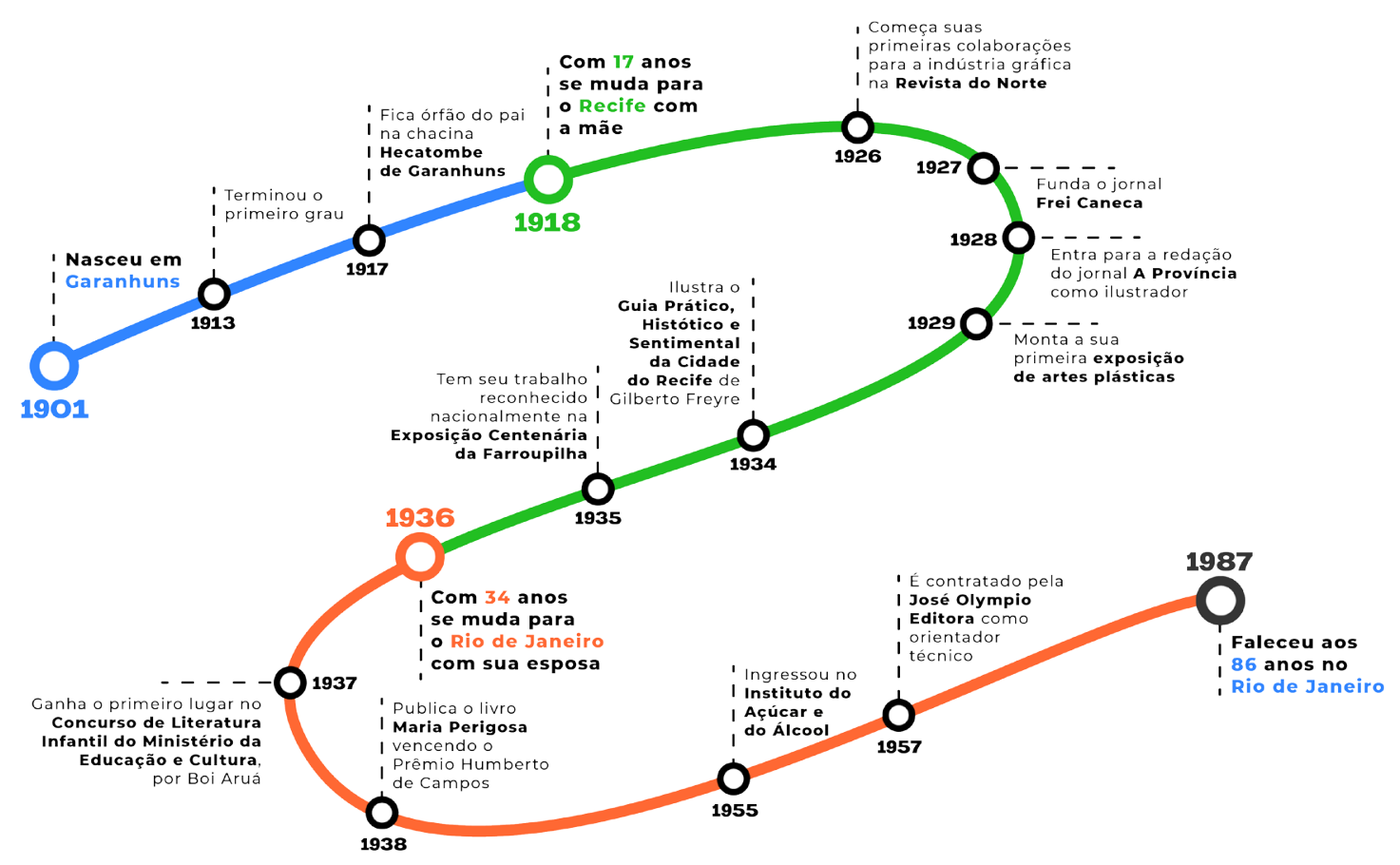

Cruzando os dados desses dois arquivos, a linha do tempo e a catalogação primária, e tendo em vista os objetivos da pesquisa, conseguimos traçar uma narrativa biográfica e cronológica da trajetória de Luís Jardim, sendo essa uma ferramenta importante na condução da pesquisa como um todo e também auxiliando na identificação dos primeiros acervos a serem visitados posteriormente.

\section{Visitando acervos}

A visita aos acervos e arquivos é uma prática essencial do pesquisador que busca desvendar os fatos com base em documentos históricos. Esse tipo de prática, comum aos historiadores, é uma das etapas imprescindíveis das pesquisas em memória gráfica. Contudo, por se tratar de uma atividade a qual muitas vezes o pesquisador em Design não tem experiência, buscar vivências semelhantes e orientações que possam auxiliar na exploração nos acervos de forma mais ordenada e precisa é uma ótima estratégia. 
Antes de partir para o primeiro destino nos acervos físicos, debruçamo-nos sobre o site da Biblioteca Nacional (BN), um dos acervos online utilizados nesta pesquisa. A hemeroteca digital da BN possui um material significativo de periódicos digitalizados de todo o Brasil, disponíveis gratuitamente para consulta. As pesquisas foram realizadas nas três abas do site, Periódico, Período e Local, utilizando inicialmente palavras-chave como "Luís Jardim" e "Luiz Jardim".

A pesquisa inicial à hemeroteca digital, antes das visitas aos acervos físicos, foi relevante por apresentar certos achados que a bibliografia não havia mostrado até então, através de citações do seu nome em jornais e revistas constatamos que o artista colaborou em diversos outros impressos, os quais foram identificados mais tarde nas visitas aos acervos físicos e catalogados para esta pesquisa.

Uma ferramenta essencial, elaborada nesta fase foi um inventário de assinaturas de Luís Jardim, construído por meio das obras encontradas nesse acervo digital (Figura 1). Todo esse material de rubricas e assinaturas serviram como um manual para a identificação de outros desenhos não creditados, presente nos impressos encontrados posteriormente.

Figura 1: Conjunto de assinaturas de Luís Jardim.

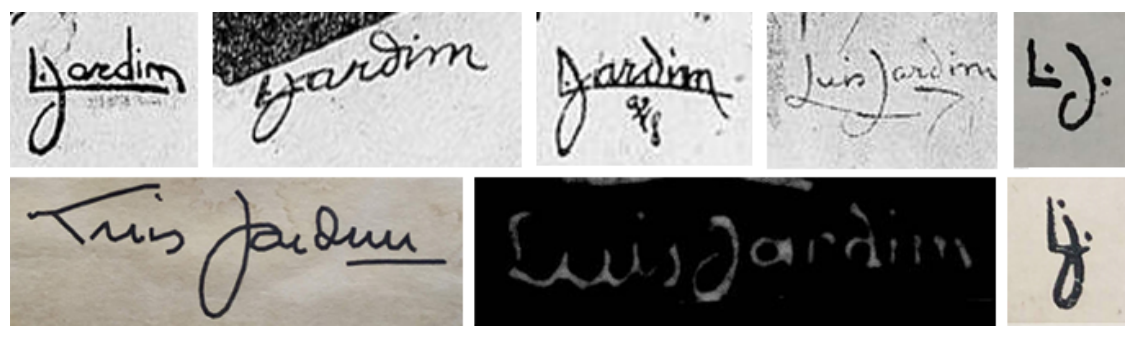

Foram localizados três acervos nas cidade do Recife: Biblioteca Central Blanche Knopf localizada na Fundação Joaquim Nabuco (FUNDAJ), Biblioteca Pública do Estado de Pernambuco (BPE) e Arquivo Público Estadual Jordão Emerenciano (APEJE). Os acervos foram visitados, mais de uma vez, em busca do material, sempre portando algumas ferramentas como celular com câmera fotográfica para registro das peças, luvas e máscaras para proteção. No gráfico (Gráfico 3) a seguir resumimos os acervos visitados e os achados: 
Gráfico 3: Mapa dos acervos físicos visitados durante a pesquisa.

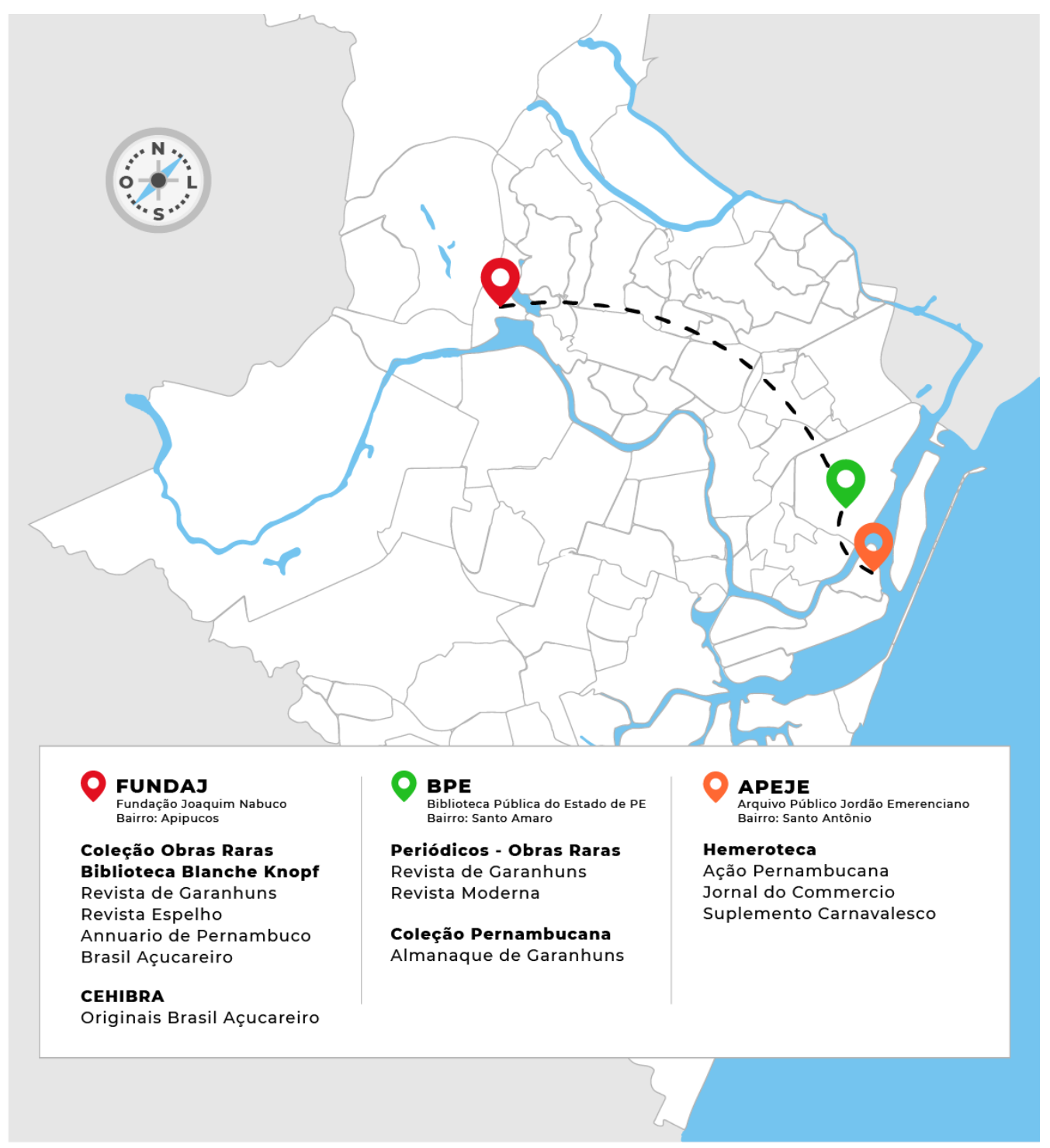

Como observado no gráfico, mais de uma coleção foi visitada em cada acervo em busca de material (infelizmente não foi encontrado material referente a Luís Jardim no Anexo da APEJE, por esse motivo não entrou no gráfico). A FUNDAJ foi o acervo com mais material coletado, só da Brasil Açucareiro fotografamos 47 imagens em 18 edições da revista, além da coleção própria do artista encontrada na Coordenação Geral de Estudos da História Brasileira Rodrigo Melo Franco de Andrade (CEHIBRA), a qual possui desenhos originais de Luís Jardim feitos para a revista Brasil Açucareiro.

\section{Catalogação e categorização}

As visitas aos acervos físicos renderam bastante material, um montante de mais de 250 imagens, a maioria delas repetidas, já que para evitar a perda de algum detalhe nas ilustrações, cada uma foi fotografada mais de uma vez. Posteriormente, quando essas fotografias foram descarregadas num computador, teve início o processo de escolha de quais se apresentaram de forma mais legível e semelhante aos originais. Nesse processo, restaram 
um total de 90 imagens, uma para cada ilustração. Somada às imagens já digitalizadas encontradas no acervo online da Biblioteca Nacional (28), obtivemos assim um total de 118 imagens.

Tendo em vista que as imagens se apresentavam tão distintas no que concerne seu tipo; acervo; periódico a qual se originava; data e local onde tais publicações pertenciam, a princípio as agrupamos em pastas e subpastas em uma forma de organização. Sendo assim, categorizamos todo o nosso acervo em três grandes grupos: [1] Periódicos de Pernambuco (1928-1936); [2] Periódicos do Rio de Janeiro (1937-1954); [3] Brasil Açucareiro (1957-1972).

Dividimos suas produções dessa forma como uma estratégia de organização do montante de imagens e a possibilidade de se fazer os recortes necessários. Sempre tendo em vista tanto o foco da pesquisa (grupo [1] Periódicos de Pernambuco), tanto a construção do site que objetiva um panorama cronológico das produções do artista.

As imagens também ganharam uma organização sistemática, sendo nomeadas por códigos que as melhor sintetizasse e identificasse-as nas pastas. Desta forma, elaboramos algumas legendas comuns a todos os arquivos e as nomeações puderam ser feitas baseado nesse esquema, seguindo sempre a mesma ordem, mas se adequando a cada artefato diferente, como orientado pelo método de Fonseca et al. (2016).

A ordem de nomeação se baseou em abreviar o nome do impresso em siglas, seguido de ano, edição, volume, número, página onde se encontrava a imagem dentro do periódico, sigla do acervo e o ano de publicação, no caso das imagens as quais não tinha a indicação da página, colocamos em ordem crescente e utilizamos a sigla IMG para definir imagem. Sendo assim, o arquivo nomeado como: "PR_A57_N192_P03_BN_1928”, por exemplo, se refere a imagem de A Província, ano 57, número 192, localizada na página 3 , a qual se encontra no acervo da Biblioteca Nacional, do ano de 1928.

\section{Fichas e metadados}

Com o acervo organizado de forma sistemática, foi elaborada fichas de coleta de dados das imagens e, consequentemente, dos impressos. Fichas desse tipo são bastante importantes na condução das pesquisas históricas em design, elas estão presentes na maioria dos estudos de Memória Gráfica e auxiliam os pesquisadores de Design da Informação no gerenciamento dessas pesquisas, seja na coleta de dados dos impressos ou nas análises gráficas das imagens. Para Farias e Braga (2018, p.12) "coletar imagens e organizá-las, algumas vezes dando origem a sofisticadas bases de dados digitais, é um passo necessário para a maioria dos projetos de pesquisa sobre memória gráfica."

Em "Proposta de ficha de coleta de dados para análise de acervos de imagens" apresentado no CIDI 2017 por Luiza Avelar Moreira e Letícia Pedruzzi Fonseca, as autoras discutem a elaboração de uma ficha de coleta de dados digital para análise de acervos de imagens tendo como objetivos a padronização, agilidade dessa coleta e validação das análises por meio da sistematização de procedimentos e tratamentos estatísticos de dados. O trabalho é bastante elucidativo, servindo de referência para a ficha desenvolvida aqui. 
Já o artigo "Metadados para a descrição de recursos de informação eletrônica: utilização do padrão Dublin Core", dos autores Marcia Souza, Laurimar Vendrusculo e Geane Melo, publicado em 2000 na revista científica Ciência da Informação também serviu de arcabouço teórico para construção de nossa ficha, tendo em vista que o que é proposto aqui é levantar informações sobre os dados coletados, através de metadados.

Os autores relatam que o conjunto de metadados proposto em seu estudo é equivalente a uma ficha catalográfica, fornecendo um conjunto simples de variáveis que podem ser utilizadas por catalogadores para simples descrição de recursos de informação. Na definição apresentada pelos autores, "Metadado significa dado sobre o dado. É a catalogação do dado" (Souza et al, 2000, p. 93). Levando isso em consideração, definimos variáveis em forma de metadados (informações sobre) para cada dado (as imagens do nosso acervo) que compuseram nossas fichas de análise.

Cada elemento de metadados que compõem as fichas foi adaptado ao universo do Design, aos objetivos da pesquisa e aos artefatos a que se destinam. A ficha foi dividida em duas sessões: informações sobre o impresso como: Categoria, Título, Edição, Data de publicação, Formato, Local de impressão, Acervo; e a segunda categoria que se destina ao item em si, a obra do artista, são elas: Tipo, Técnica de produção, Cor, Assinatura do artista, Legenda, Tipologia/Tema, Elementos que compõem a imagem.

Figura 2: Exemplo de ficha utilizada nas análises.

FICHA DE ANÁLISE PERNAMBUCO LUÍS JARDIM
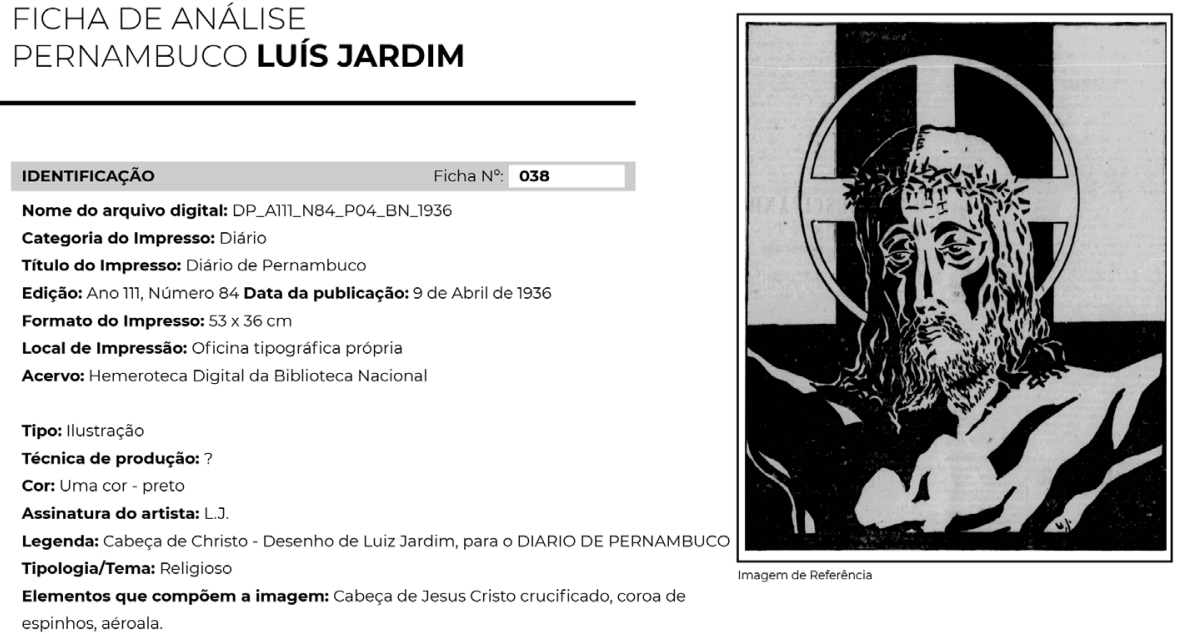

espinhos, aéroala.

Os elementos que compõem a primeira sessão de informações sobre o impresso foram preenchidos com base na coletânea de publicações de Luiz do Nascimento, História da Imprensa de Pernambuco (1821 - 1954), as quais possuem uma vasta gama de dados sobre a imprensa pernambucana. Esses elementos de metadados auxiliaram na obtenção de novos dados, por exemplo, compreender formatos de periódicos, para quais categorias de impressos o artista mais colaborou, ou até levantar questões sobre as práticas de impressão desses impressos, além de, é claro, auxiliar na organização do acervo como um todo. 
Já a segunda sessão da ficha se atém às imagens produzidas por Jardim, os resultados que se espera obter a partir dos elementos dessa sessão vão das técnicas comumente utilizadas (quando indicada e identificada nos próprios impressos), os temas mais comuns em que o artista desenvolveu seus trabalhos, diferentes formas de assinar seu nome (como já mencionado, de extrema importância na busca de novas imagens), utilização de cores nos impressos e os tipos de projeto, como: ilustração, capa, tipografia, etc., contribuindo para uma maior compreensão das técnicas e parque gráfico que eram oferecidos à época e com os quais o artista se relacionava.

\section{Análise estatística dos dados}

Os dados foram tabulados a partir das fichas de análise, onde cada célula da tabela ganhou a informação correspondente a cada variável da ficha. Modificações foram necessárias para se adequar a essa tabulação, como apontado por Fonseca et al. (2016), algumas informações qualitativas acabam gerando colunas muito largas e um tempo longo para inseri-las nas tabelas, sendo sugerido a substituição por códigos numéricos, foi o caso, por exemplo, dos acervos em que foi mantido a sigla de cada um.

Alguns exemplos dessas substituições no momento da tabela são: a data do impresso, substituída apenas pelo ano em que cada impresso foi feito, porém na ficha a informação do dia, mês e ano foi mantida. Em "legenda", já que em alguns casos as legendas são muito extensas, colocamos na tabela o trecho em que menciona o nome do artista, por uma questão de autoria, que iremos discutir posteriormente. Mantivemos as informações de descrição das imagens apenas nas fichas, por essa ter uma função apenas descritiva e, assim sendo, ser extensa demais para as células das tabelas.

Ao final da tabulação é comum transformá-las em gráficos para análises estatísticas dos dados, os gráficos podem ser uma ótima ferramenta de argumentação, além de traduzir um volume grande de informações em uma comunicação visual e verbal de forma acessível. Sendo assim, os autores do método que seguimos comentam as interferências do Design da Informação nesse processo:

Neste método, os procedimentos teóricos-metodológicos do design da informação acompanham o pesquisador na condução de três etapas da pesquisa: a elaboração da ficha de análise do impresso, a análise dos dados coletados e, por fim, a discussão dos resultados da pesquisa. Nesses três momentos, o pesquisador assume o papel do designer da informação (infodesigner) ao passo que se encarrega de selecionar e organizar informações (Wilbur \& Burke, 1998), com a tarefa de registrar e garantir eficiência da investigação científica (Fonseca et al, 2016, p. 151).

Criamos um infográfico agrupando os diversos dados que o procedimento gerou, auxiliando na visualização completa das informações aliada a uma síntese visual: 
Gráfico 4: Infográfico com os resultados da tabulação dos dados.

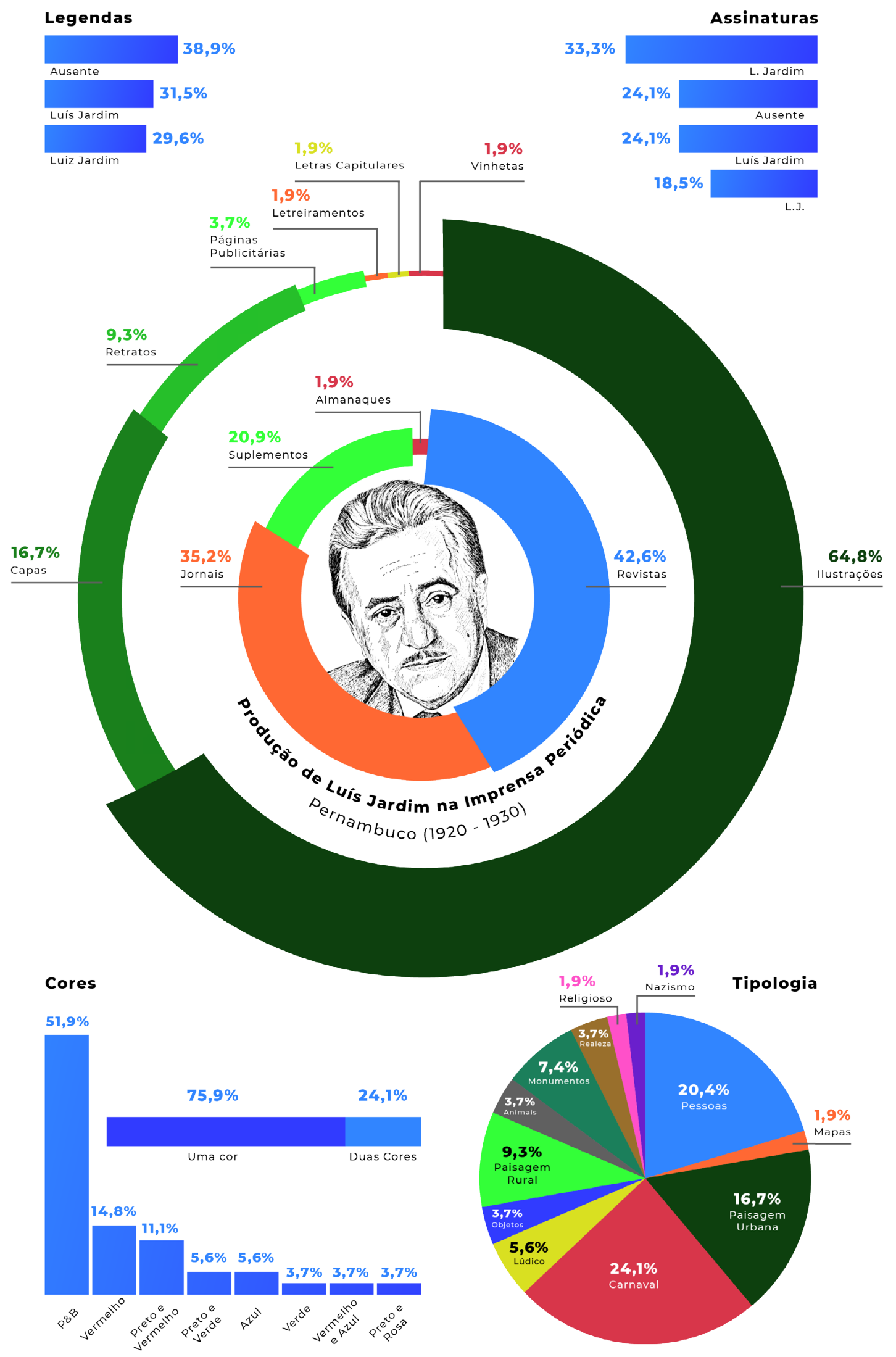




\section{Discussão dos resultados}

A partir do gráfico chegamos a algumas discussões acerca da produção de Jardim no período, Fonseca et al (2016) recomenda que as discussões tenham sempre em vista os objetivos da pesquisa. Na dissertação (Verissimo, 2020) apresentamos comentários sobre as configurações formais das imagens, buscando evidenciar estilos e linguagens gráficas adotados pelo artista em seus primeiros trabalhos, assim como alguns aspectos tecnológicos. Contudo, neste artigo o nosso objetivo é a criação de um banco de dados online, isto posto iremos nos ater aos dados apresentados nos gráficos e como os mesmos auxiliaram na próxima etapa, a construção do site.

Os dados referentes a assinatura do artista e legenda das imagens, por exemplo, mostram como, neste tipo de pesquisa do ponto de vista de um artista gráfico, tanto a legenda como a assinatura do artista auxiliam na autoria das imagens. Portanto, utilizar um conjunto de assinaturas como ferramenta na identificação de possíveis obras de Luís Jardim foi bastante útil, já que o mesmo assinava seu nome em diversas combinações diferentes. Assim como, seu nome é encontrado nas legendas das imagens ora como Luís com " $s$ ", ora como Luiz com " $z$ ", fato esse percebido logo no início das pesquisas nos sistemas de buscas de acervos online e sempre verificados nas duas grafias desde então.

O gráfico circular no centro da imagem (Gráfico 4) representa os dados referentes a participação de Jardim nos periódicos e sua produção nos mesmos, sendo jornais e revistas os meios em que mais colaborou (um total de quase $80 \%$ do total) e seu trabalho com ilustrações sendo o de maior recorrência, seguido das capas e retratos que produziu.

Desse conteúdo, observa-se as cores em que foram aplicadas em sua impressão, há uma predominância do uso de apenas uma cor, como vista na parte inferior do infográfico, com domínio do preto e branco (P\&B), sendo o branco a superfície do papel, seguido da cor vermelha, presente em boa parte de suas produções.

Por último, agrupamos as imagens por temas e tipologias, sendo os de maior ocorrência as imagens de carnaval; representando pessoas; paisagem urbana e rural; e monumentos. As imagens de carnaval em sua maioria são as ilustrações de fantasias que Jardim ilustrou para o Suplemento Carnavalesco do Jornal do Commercio, algumas das imagens representando pessoas são retratos de personalidades que Jardim criou. Já a grande maioria de paisagens urbanas, rurais e monumentos pode-se inferir como uma consequência da participação de Jardim para o Guia de Recife, de Gilberto Freyre, o qual possuía diversas ilustrações feitas por Jardim sobre esse tema.

Esses resultados atestam a capacidade inventiva de Luís Jardim como ilustrador e artista gráfico. Sua versatilidade, como já pontuado, foi uma característica bastante explorada pela indústria, além de seu conhecimento no manejo das tecnologias presentes à época.

\section{Construção o site}

Como comentado anteriormente, a criação de um banco de dados resultado da catalogação partiu do princípio de inserir os artefatos gráficos na sociedade, conforme sugerido por Farias e 
Braga (2018). Além de, também, atuar como ferramenta de difusão da pesquisa científica e da obra do artista como um todo. Dessa forma, a construção do site surgiu como última etapa, complementando o método de Fonseca et al (2016).

$\mathrm{Na}$ curadoria das imagens que iriam para o site, organizamos o acervo desta forma (Tabela 1), não ignorando as imagens dos grupos [2] Periódicos do Rio de Janeiro (1937-1954) e [3] Brasil Açucareiro (1957-1972), contudo dando maior ênfase a sua produção em Pernambuco, incluindo imagens do Guia Prático, Histórico e Sentimental da Cidade do Recife, tendo em vista a importância que esse trabalho teve em sua produção. Também, agrupamos as imagens do Suplemento Carnavalesco às capas do Jornal do Commercio, já que o suplemento pertencia ao jornal.

Tabela 1: Catalogação das imagens escolhidas para o acervo do site.

\begin{tabular}{lll}
\hline Ano & Título do periódico & No de imagens \\
\hline $1928 / 1930$ & A Província & 6 \\
$1930 / 1931$ & Revista de Garanhuns & 20 \\
1933 & Revista Moderna & 2 \\
1934 & Ação Pernambucana & 1 \\
1934 & Guia do Recife & 8 \\
1936 & Annuario de Pernambuco & 1 \\
$1935 / 1936$ & Diário de Pernambuco & 6 \\
1936 & Jornal do Commercio & 14 \\
$1957 / 1972$ & Revista Brasil Açucareiro & 3 \\
$1937 / 1954$ & (Rio de Janeiro) & 6 \\
& & Total: $\mathbf{6 7}$ \\
\hline
\end{tabular}

Nessa etapa também houve um retorno no contato aos acervos, na forma de solicitação de autorização das imagens a serem disponibilizadas no site, sabemos da importância dessa autorização tendo em vista que, em alguns casos, as imagens possuem direitos autorais.

Para a construção do site, alguns dados da pesquisa foram essenciais, a linha do tempo auxiliou na visualização das imagens de forma temporal. Podendo o usuário navegar pelo site desde suas primeiras produções na imprensa de Pernambuco até as últimas, através de um menu. Assim como, alguns gráficos, como a própria linha do tempo, foram incorporados à página inicial do site, com um texto introdutório apresentando de forma resumida a biografia do artista.

Alguns dados das análises auxiliaram na escolha da imagem principal da home do site (Figura 3), a mesma extraída da capa do Jornal do Commercio, representa o carnaval, um dos temas mais presentes nas obras de Jardim no período, como visto anteriormente. 
Figura 3: Captura de tela da home do site "O design de Luís Jardim".

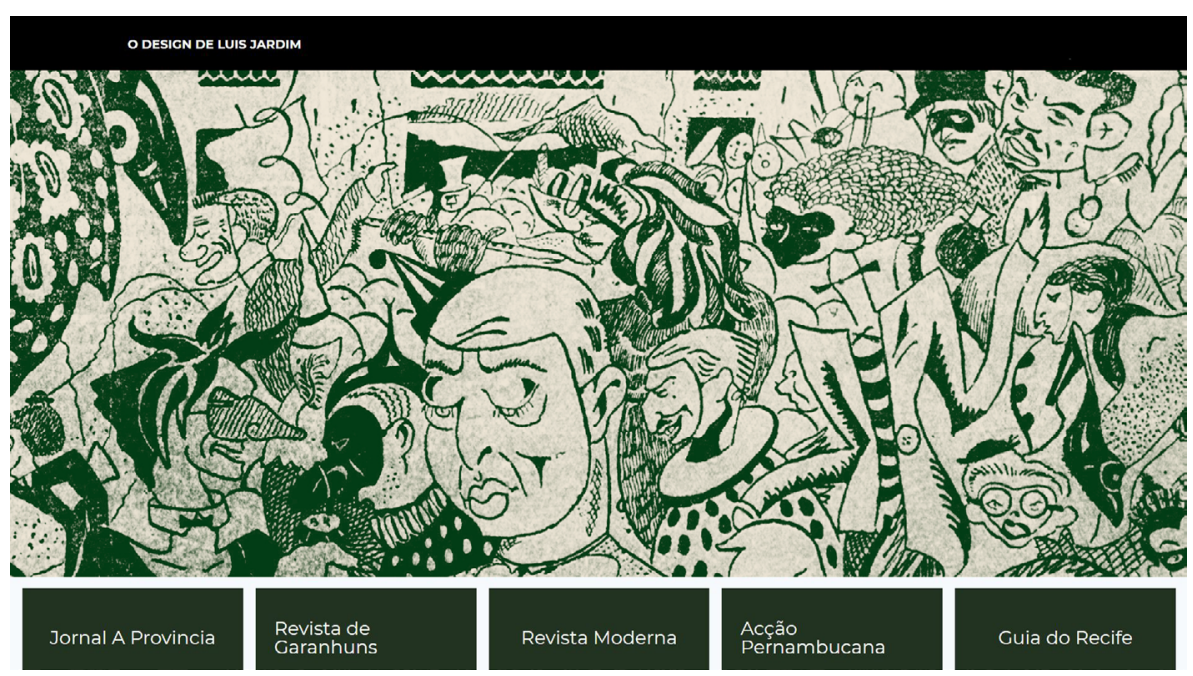

O site também cumpriu o papel primordial de utilizar uma interface acessível e responsiva, funcionando sem distorção de imagens, tanto na navegação desktop, quanto mobile. As imagens, presentes nesse banco de dados digital, possuem seus tamanhos originais, na qualidade em que foram fotografadas nos acervos, bem como legendas as identificando. Ficando disponíveis para futuros pesquisadores que contemplem as obras de Luís Jardim e a Memória Gráfica.

O site "O Design de Luís Jardim" (https://www.luisjardim.com.br/) foi financiado pela premiação de ações artísticas e culturais do Edital Criação, Fruição e Difusão - LAB PE, sendo essa uma realização da Secretaria de Cultura do Estado de Pernambuco - SECULT-PE em conformidade com a Lei n 14.017/2020 - Lei Aldir Blanc, e está disponível para acesso.

\section{Considerações finais}

Este artigo teve como objetivo fazer um relato do processo metodológico da catalogação da obra de Luís Jardim em Pernambuco e a construção do site como difusão de suas primeiras produções. Para isso foi levantado um relato biográfico resumido do artista, contando um pouco sobre suas colaborações para a indústria gráfica pernambucana, por meio da bibliografia foi possível conhecer um pouco sobre o artista e o contexto histórico vivido pelo mesmo nas primeiras décadas do século XX.

O método utilizado durante a pesquisa auxiliou na condução da mesma de forma sistemática, além disso, as sugestões e modificações ao "Conjunto Metodológico para Pesquisa em História do Design a partir de Materiais Impressos" (2016) auxiliaram na adaptação para uma pesquisa feita sobre o ponto de vista de um artista gráfico. Dessa forma, etapas e ferramentas como a linha do tempo, o conjunto de assinaturas de Luís Jardim e estratégias próprias de busca em acervos pelo seu nome nas duas grafias, por exemplo, foram imprescindíveis do ponto de vista estratégico da investigação científica. 
As adaptações ao método também permitiram que os pesquisadores desempenhassem o papel de designer da informação, selecionando e organizando informações por meio de gráficos, infográficos e fichas, sendo essas, ferramentas de significativo valor para visualização da condução da pesquisa e verificação dos dados.

Por fim, a construção do site visou a difusão e, consequentemente, a continuidade das pesquisas acerca de Luís Jardim e da Memória Gráfica de Pernambuco. Disponibilizando assim, um acervo online para futuros pesquisadores e admiradores das artes gráficas, reinserindo as produções do artista na memória local e, deste modo, contribuindo com a compreensão de suas identidades, as quais estão em constante processo de transformação.

\section{Referências}

Cardoso, R. (2018). Memória Gráfica no Agreste (Cap. 2, pp. 9-11). Recife: CEPE.

Farias, P., Braga, M. C. (2018). Dez ensaios sobre memória gráfica. São Paulo: Blucher.

Fonseca, L., Gomes, D., Campos, A. (2016) Conjunto Metodológico para Pesquisa em História do Design a partir de Materiais Impressos. Infodesign, 16, 142-161.

Hélio, M., Bruscky, P. (1998). Vida, arte, palavra, perfis de Luís Jardim. Recife: Fundarpe.

Instituto do Patrimônio Histórico e Artístico Nacional (2007). Iphan completa 70 anos de proteção da memória brasileira. Disponível em: http://portal.iphan.gov.br/noticias/detalhes/1774/iphan-completa-70-anos-de-protecao-damemoria-bra

Krenak, A. (2019). Ideias para adiar o fim do mundo. São Paulo: Companhia das Letras.

Moreira, L. A., Fonseca, L.P., (2017). Proposta de ficha de coleta de dados para análise de acervos de imagens. Anais do Congresso Internacional de Design da Informação, 8, 12081224. DOI 10.5151/cidi2017-114

Nascimento, L. (1966). História da Imprensa de Pernambuco (1821-1954) Vol II Diários do Recife - 1829/1900. Recife: Imprensa Universitária.

Nascimento, L. (1967). História da Imprensa de Pernambuco (1821-1954) Vol III Diários do Recife - 1901/1954. Recife: Imprensa Universitária.

Nascimento, L. (1994) História da Imprensa de Pernambuco (1821-1954) Vol XII Municípios das Letras $E$ a J. Recife: Imprensa Universitária.

Souza, M. I. F., Vendrusculo, L. G., Melo, G. C. Metadados para a descrição de recursos de informação eletrônica: utilização do padrão Dublin Core. Ciência da Informação, 29, 93-102.

Verissimo, B. P., Campello, S. R. B. B. (2019) Memória Gráfica de Pernambuco: Luís Jardim sob a ótica do design da informação. Anais do Congresso Internacional de Design da Informação, 9, 2375-2385. DOI 10.5151/9cidi-congic-5.0272

Verissimo, B. P. (2020) O design de Luís Jardim: ilustrações e artes gráficas para a imprensa periódica pernambucana do começo do século XX [Dissertação de Mestrado]. Universidade Federal de Pernambuco, Recife. 